\title{
Fitting Technology To The Mathematics Pedagogy: Its Effect On Students' Academic Achievement
}

\author{
Leila R. Gano, University of the East, Philippines
}

\begin{abstract}
Taking advantage of student's passion in using technology in the form of digital media sets the trend of this study. If this passion can be harnessed, digital media may have an important and powerful role to play in education. A methodology of teaching using digital media in the form of $V C D$ is experimented and tested for possible effect on student's academic achievement. With Gagne's nine-instructional events as guide in the pedagogical process, the researcher implemented Self-study video (SSV) in teaching College Algebra to twenty-one (21) tertiary students of University of the East. Two groups of students are used as subject, one taught using the traditional method and the other taught by the Self-study video method. It is the purpose of this study to compare the academic achievement of the two groups of students and determine their perception as regards their learning experience in the SSV in terms of Level of Discussion, Level of Demonstration, Viewing Experiences and Level of Effectiveness.
\end{abstract}

Keywords: Technology; Mathematics; Pedagogy; Academic Achievement

\section{INTRODUCTION}

nteraction with digital media has become commonplace for students during this modern age of education.
Mobile phones with built-in cameras have become increasingly popular and are now considered
necessities rather than luxuries. The present generation demands freedom to interact with digital imagery anytime, anywhere that it has become common knowledge to use, possess and master its usage. If this passion can be harnessed, digital media may have an important and powerful role to play in education, considering the hands-on time that the everyday youth has on it.

Fortunately, there is an ongoing shift in the educational system and the way it delivers its educational content due to advances and development in technology from the traditional to technology-assisted teaching. Digital media, specifically video, has become a powerful medium for teaching and learning. Videos can be used to present and illustrate educational materials as it can complement textual content, classroom lectures and face-to-face discussions. In essence, it has become a tool for effective and efficient communication; not replacing, but augmenting the existing educational infrastructure making it more effective and efficient.

Using technology to enhance the pedagogical (teaching) process involves more than just learning how to use specific pieces of hardware and software. It requires an understanding of pedagogical principles that are specific to the use of technology in an instructional setting. This would entail the proper selection of types of technology to use, how to properly integrate them into the present processes, provide proper training and time for acclimation for both the instructor and the students, and continuously assess and improve the process and make it a robust one.

The researcher looked into two (2) learning theories that explains and supports the two pedagogical processes that is used in this study: the Instructivism theory and the Constructivism theory. 


\section{Traditional Method Of Teaching And Instructivism}

The traditional method of teaching is teacher-centered. This methodology is influenced by the Instructivism theory of learning wherein knowledge is passively attained by the learner from the teacher. The instructivist teacher has the responsibility of obtaining the knowledge and controlling the learning process by transferring knowledge to the learner. This idea emphasizes that knowledge is external to the learner. It may be noticed that in this approach the teacher is the figure of authority, the dispenser of knowledge and that the learner's mode of receiving knowledge is passive.

Diaz $^{\mathrm{i}}$ opined that an instructivist view of teaching/learning promotes three predominate types of communication. According to instructivist principles, learning flows in a mostly unidirectional path, proceeding from the knowledgeable authority (teacher), or from instructional content, to the passive learner.

Through time, the traditional method has proven its effectiveness in the teaching learning process. This may be the reason why most teachers still use the traditional lecture as an instructional strategy resulting to traditional student dependent learning styles.

\section{Self-Study Video And Constructivism}

Teaching by Self-study video requires that students learn by watching film clips discussing the topics of the course. Students may watch the video in a computer or in video players, depending upon the format of the video. In this learning environment, the students received information by watching the lectures embedded in the video, either alone or in groups. Instead of being passive recipients of information and knowledge, students become more active in the learning process and are placed closer to the center of the instructional experience.

This methodology is patterned after the Constructivism theory of learning. According to the constructivist approach $^{\text {ii }}$, teachers become guides rather than dispensers of knowledge, and instructional practice places more importance on the role of the student in constructing knowledge. Thus, the adult learning theory paradigm has shifted from a teacher-centered towards a learner-centered environment. Using this approach, teachers can employ collaborative learning techniques that allow students to combine efforts at solving a problem, or in task management.

Technology-assisted teaching, in this study self-study video (SSV), is not simple. It requires advanced planning and preparation on the part of the teacher to fit technology into the pedagogy. To fit technology into the pedagogy, a faculty needs to decide what and when to use the technology and how to integrate it in teaching the lessons. If the faculty cannot successfully formulate fitting technology into the pedagogy there is less chance for learning on the part of the students. Expertise of the faculty on technology-assisted instruction may have direct effects to student's academic achievement. Thus, the purpose of this study is to determine the effects of fitting technology into the pedagogy of teaching College Algebra on student's academic achievement. An experimental research is conducted on two groups of students, one taught using the traditional method and the other taught by the Self-study video method. It is the purpose of this study to compare the academic achievement of the two groups of students and determine their perception as regards their learning experience in the SSV.

\section{THEORETICAL FRAMEWORK}

In this study of fitting technology to the pedagogy, Robert Gagne's "Conditions of Learning" is used for the framework. Central to Gagne's theory is that design of instruction must be in the context of the learner's need. Instructional method must be varied in order to meet the needs of different learners. The pedagogical aspect of this study is centered around Gagne's nine-step process called Nine Events of Instruction. These nine events of instruction guided the researcher in the conduct of this present study. 
Table 1: Instructional Events and the Associated Self-study Video Activities

\begin{tabular}{|c|c|}
\hline Instructional Event & Activity \\
\hline $\begin{array}{l}\text { 1. Gain attention. For learning to take place, student's } \\
\text { attention must be captured. }\end{array}$ & Distribute Midterm Grading Period Schedule of Activities \\
\hline $\begin{array}{l}\text { 2. Inform learner of the objective(s). Students must be made } \\
\text { aware of what to expect in a lesson. }\end{array}$ & Discussion of what to expect in the scheduled lesson. \\
\hline $\begin{array}{l}\text { 3. Stimulate recall of prerequisite learning. Learning occurs if } \\
\text { new information is associated with prior knowledge. }\end{array}$ & $\begin{array}{l}\text { A classroom meeting is held to recall the previous lesson and } \\
\text { connect it to the new lesson. }\end{array}$ \\
\hline $\begin{array}{l}\text { 4. Present the content. This event is where the lesson is } \\
\text { actually presented to the learner. }\end{array}$ & $\begin{array}{l}\text { Distribution of the SSV that contains the video discussion } \\
\text { format of the lesson. }\end{array}$ \\
\hline $\begin{array}{l}\text { 5. Providing learning guidance. Along with the presentation } \\
\text { of the content, additional guidance must be given to the } \\
\text { learner. }\end{array}$ & $\begin{array}{l}\text { Student undergoes learning through Self-study video which } \\
\text { can be viewed in the computer or in any video player, either } \\
\text { alone or in group. }\end{array}$ \\
\hline $\begin{array}{l}\text { 6. Eliciting the performance (practice). In this event, the } \\
\text { learner is required to confirm if learning took place or } \\
\text { correct understanding is attained. }\end{array}$ & $\begin{array}{l}\text { Included in the SSV are Exercises in Word document format. } \\
\text { Instructions are given as to WHEN to answer it, WHEN to } \\
\text { submit it, and WHERE to submit it. }\end{array}$ \\
\hline $\begin{array}{l}\text { 7. Provide feedback. Regular, specific, and immediate } \\
\text { feedback of the learner's performance is important. }\end{array}$ & $\begin{array}{l}\text { Checking, submission of Exercises included in the SSV is done } \\
\text { on a scheduled classroom meeting. Seatworks are also given. } \\
\text { This is the time for clarification and consultation between } \\
\text { teacher and students. }\end{array}$ \\
\hline $\begin{array}{l}\text { 8. Assess performance. Upon completing the lesson, the } \\
\text { learner is given a test to assess the learning outcomes. }\end{array}$ & Teacher gives a scheduled examination covering the lesson. \\
\hline $\begin{array}{l}\text { 9. Enhancing retention and transfer . Retention of lessons } \\
\text { learned is important to achieve the learning objectives. }\end{array}$ & $\begin{array}{l}\text { Feedback of quiz result is given immediately after each } \\
\text { scheduled quiz. Correct answer is given for each number in the } \\
\text { test. Question and answer session is held regarding the quiz } \\
\text { given. }\end{array}$ \\
\hline
\end{tabular}

Following all these nine instructional events complete the teaching-learning process using the self-study video.

\section{METHODOLOGY}

The study is a combination of QUANTITATIVE and QUALITATIVE research design. Quantitative research design is used to present the findings as to the academic achievement of the students in terms of score results of the midterm examination given after the implementation of the self-study video. The qualitative research design is used to discuss the steps taken by the researcher in fitting technology into the pedagogy.

The principal respondents for this research study were the students of College of Business Administration, University of the East - Manila enrolled in the course College Algebra during the second semester school year 2008-2009. They belong to MA 101 sections BNB and BHB handled by the researcher. Out of forty (40) students in each class, only twenty-one (21) students in the experimental group paired with twenty-one (21) students in the control group taking into account the following criteria of pairing/matching: same mental ability, same course, same teacher, and same morning session. The performance of the students in the Preliminary examination is considered to determine the comparability of the two groups in mental ability.

The methodology of teaching is blended wherein the use of self-study video (SSV) is fitted into the College Algebra pedagogy. The self-study video replaced the lecture time in the classroom but the assignment/clarification time of the assignment, seatwork/clarification time of the seatwork, quiz and feedback are retained.

\section{DATA GATHERING INSTRUMENT}

To determine the effects of fitting technology into the pedagogy on student's academic achievement, an examination is given at the end of the grading period to assess student's learning or achievement in the course. The examination covered the topics Rational Expressions (Fractions), Exponents and Radicals. The raw scores of the test are transformed into an interval percentage rating. After the examination scores for achievement are interpreted, the mean difference between groups is compared using t-test for independent group means. 
To determine the perception of the respondents in the experimental group as regards their learning experience under the self-study video, a survey-questionnaire is given. The survey-questionnaire tried to find out the student's perception on the following categories: the students' level of knowledge upon enrolment, level of discussion of the topics, level of demonstration of the topics, students' learning experiences with SSV, level of effectiveness of the SSV, and their learning outcomes. The questionnaire is adopted by the researcher from a survey conducted by University of the Philippines Open University (UPOU) last 2008.

\section{PROCEDURES IN GATHERING DATA}

This research study involved four phases namely:

1. Development Phase. On this phase, the researcher performed the following:

- $\quad$ Compiled the Self-study video

- $\quad$ Developed the electronic course modules used to support the Self-study video.

- $\quad$ Constructed the examination to assess student's achievement in the course.

2. Validation Phase. On this phase the following are implemented and validated:

- $\quad$ the self-study video. is expert validated. The videos are evaluated by five (5) selected mathematics faculty members of the Department of Mathematics and Statistics, College of Arts and Sciences of the University of the East - Manila. A questionnaire is also given to solicit their comments.

- $\quad$ the developed examination is analyzed, in which reliability is established with the use of the SplitHalf Reliability (0.5663) and Kuder-Richardson Reliability \& Coefficient Alpha (0.6308).

3. Implementation Phase. During this phase, the students are subjected to the implementation of the selfstudy video in the course College Algebra. No regular classroom meeting is held during this phase; instead, teaching/learning process took place with the use of the SSV at home, in computer centers, and others. However, to keep track of student's development, six (6) scheduled face-to-face meetings are held for student/teacher consultation regarding the topics in the SSV. The supervision of the examination to the students is personally handled by the researcher. Student's perception regarding their learning experience under the self-study video is gathered with a questionnaire.

4. Assessment Phase. On this phase, the effect of the SSV on student's academic achievement as evidenced by their examination score results is computed and analyzed. The student's perception as regards their learning experience under the self-study video is determined.

\section{STATISTICAL TREATMENT OF DATA}

To determine the effect of fitting of technology into the pedagogy on the academic achievement of the students, the following statistical treatment are used: 1) T-test for independent variables - to determine the effect of the SSV on students academic achievement, to test for the significance of the differences between the mean scores of the examination scores; 2) Correlation - to determine/establish the reliability of the constructed examination; 3 ) Percentage - to compute for the percent equivalent of the students' score result in the examination; 4) Mean - to compute for the mean grade of the distribution; and 5) Standard Deviation - to determine and compare the variability of the student's grades.

\section{FINDINGS OF THE STUDY}

\section{Preparations Done By The Researcher To Fit Technology To The Pedagogy}

Initial preparation involved the planning of activities for the whole midterm grading period. The term consists of six (6) weeks equivalent to eighteen (18) hours for a three (3)-unit subject. For the midterm grading period, the course College Algebra covered the following topics: 
- Rational Expressions (Fractions). This lesson discusses fractions that involved polynomials in the numerator, or in the denominator, or both. At the end of the lesson, the students must know how to simplify fractions and be able to perform the four fundamental operations (addition, subtraction, multiplication and division) on fractions.

- $\quad$ Exponents. This lesson discusses integral (positive, negative and zero) exponents and rational (fractional) exponents.

- $\quad$ Radicals. This lesson discusses simplifying radical and radical expressions, operations on radical expressions and rationalizing radicals and radical expressions.

Students are given a printed copy of the Midterm Grading Period Schedule of Activities to make sure that they are well-informed as to the date, the topic, the particulars of the lessons and the teaching strategy/venue (whether classroom of SSV).

\section{Students' Academic Achievement In The Course College Algebra}

For the academic achievement of the students in the traditional method, the maximum grade is 96 , with minimum grade of 58. For the SSV, the maximum grade is 99 and the minimum is 56. The median grade for both groups is 75 . Looking into the mean grades, the traditional group is 77.33 which is a little bit higher than the SSV group of 77.05 The grades of the students in the traditional method is less dispersed (standard deviation $=11.46)$ than the grades of the SSV students (standard deviation = 14.33). However, looking deeply into the result, computing for the first quartile revealed that $25 \%$ of the percentage grades of the students are less than or equal to $68.50(5.00)$.

Furthermore, arranging the students' grades in an array ascendingly showed that $47.62 \%$ of the grades are less than or equal to 74 .

Table 2: Students' Academic Achievement In The Course College Algebra

\begin{tabular}{|c|c|c|c|c|}
\hline \multirow{2}{*}{ Grades Interval } & \multicolumn{2}{|c|}{ Traditional Method } & \multicolumn{2}{|c|}{ Self-Study Method } \\
\hline & Frequency & Percentage & Frequency & Percentage \\
\hline $1.25-1.00 \quad$ (Excellent) & 1 & 5 & 3 & 14 \\
\hline $1.50-1.75 \quad$ (Very Good) & 4 & 19 & 2 & 10 \\
\hline $2.00-2.25 \quad($ Good $)$ & 2 & 10 & 3 & 14 \\
\hline $2.50-3.00 \quad$ (Fair) & 4 & 19 & 3 & 14 \\
\hline (Poor-Failure) & 10 & 48 & 10 & 48 \\
\hline TOTAL & 21 & 100 & 21 & 100 \\
\hline
\end{tabular}

Table 2 displays the academic achievement of the two groups of students expressed in its equivalent grade point and groups by grades interval.

In the traditional method, only one (1) or 5\% of the students performed excellently with a grade of 1.25 1.00. An equal number of four (4) or $19 \%$ were very good and were fair. Two (2) of the twenty-one (21) students were good with grades bracket of $2.00-2.25$.

In the SSV method, three (3) or $14 \%$ of the students performed excellently. The same number of students, equivalent to three (3), got grades of 2.00-2.25 and 2.50-3.00, verbally interpreted as good and fair, respectively.

For both group of students, it is very important to note that ten (10) or $48 \%$ performed poorly with a grade point equivalent to 5.00 . 
Comparison Between The Academic Achievement Of The Students In The Traditional Method And The SelfStudy Method

Table 3: Comparison Between The Academic Achievement Of The Students In The Traditional Method And Self-Study Video Method

\begin{tabular}{|l|c|c|c|c|}
\hline Academic Achievement & Mean Grade & Difference & p-value & Significance \\
\hline Traditional Methods & 77.29 & 0.13 & \multirow{2}{*}{0.97} & Not Significant \\
\hline Self-Study Method & 77.16 & 0.13 & & \\
\hline
\end{tabular}

Findings show that the mean grade of 77.29 of the students in the traditional method and 77.16 of the students in the self-study method gave a computed p-value of 0.97 . This means that the difference of 0.13 is not significant. The researcher found no enough evidence to reject the null hypothesis at 0.05 level of significance.

The mean difference obtained led the researcher to accept the null hypothesis, which means that there is not significant difference between the academic achievement of the students taught by traditional method and the students taught by self-study video method.

The overall findings reveal that for both group of students, $52 \%$ received passing marks or grades, while $48 \%$ got poor or failing grades. To have an in-depth analysis of these results, the research tried to look into comparative difference between the good performing students with passing grades and between poorly performing students with failing grades.

Table 4: Significant Difference Between The Academic Achievement Of The Students In The Traditional Method And Self-Study Method (Passing Grades)

\begin{tabular}{|l|c|c|c|c|}
\hline Academic Achievement & Mean Grade & Difference & p-value & Significance \\
\hline Traditional Methods & 86.32 & 2.04 & 0.56 & \multirow{2}{*}{ Not Significant } \\
\hline Self-Study Method & 88.36 & & & \\
\hline
\end{tabular}

T-test between the passing grades academic achievement of the two groups of students still showed no significant difference. The p-value of 0.56 is greater than the 0.05 level of significance.

Table 5: Significant Difference Between The Academic Achievement Of The Students In The Traditional Method And Self-Study Method (Failing Grades)

\begin{tabular}{|l|c|c|c|c|}
\hline Academic Achievement & Mean Grade & Difference & p-value & Significance \\
\hline Traditional Methods & 67.36 & 2.52 & \multirow{2}{*}{0.33} & Not Significant \\
\hline Self-Study Method & 64.84 & & & \\
\hline
\end{tabular}

Findings showed that the difference of 2.52 between the grades of the students in the traditional method (67.36) and self-study method (64.84) is not significant. The resulting computed p-value of 0.33 is greater than the 0.05 level of significance. T-test using the equivalent point grade is not possible as there is no variability in the grades of the students. All failing grades are equivalent to 5.00.

The results of the t-tests showed that the use of SSV, fitting it to the mathematics pedagogy does not affect students' academic achievement. The performance of the students in the traditional method is the same as the student that undergo learning through the use of self-study video. The finding also emphasized that pedagogy with technology is equally effective as the traditional method of teaching, thus, it may concluded that SSV may be used in place of the traditional method and still having the same result on the student's academic achievement. 


\section{Students' Perception As Regards Their Learning Experience Under The Self-Study Video In The Course College Algebra}

The discussion on student's perception is presented qualitatively (narrative) in the order they are asked in the questionnaire.

Level of Knowledge in College Algebra upon Enrolment

For the topic Fraction, from twenty-one students, four (4) have very little background, seven (7) students knew few things, another seven (7) have a working knowledge, and three (3) are familiar with the topic.

For the topic radicals, only two (2) have a little background, thirteen (13) knew a few things, five (5) have a working knowledge and only one (1) is very familiar with the topic. Radicals is a difficult topic compared to

\section{Problems Encountered with the Self-Study Video}

From twenty-one (21) students, fifteen (15) encountered no problems, while the other six (6) encountered segment with faulty sounds in the video.

How the Self-Study Video is Viewed

Twenty (20) of the students watched the Self-study video at home using their own video player. One (1) watched the SSV at the computer shop.

Level of Discussion

For the topic Fractions, four (4) students claimed that very little has been discussed in the SSV. Seven (7) said that enough has been discussed, about nine (9) said that it was well discussed and only one (1) opined that the topic Fractions is very well discussed.

For the topic Radicals, six (6) said they needed more information about the topic, nine (9) said that radicals is moderately discussed, four (4) claimed that it was well discussed, and only two (2) said it was very well discussed.

\section{Level of Demonstration}

Under Fractions, the topics "Simplifying Fractions" and "Addition and Subtraction of Fractions" are perceived by eleven (11) out of twenty-one (21) students as well-demonstrated. Ten (10) students said that "Multiplication and Division of Fraction" is moderately discussed and the remaining ten (10) said that it is well discuss.

In Radicals, the students claimed that the topics "Simplifying Radicals" (12), "Addition and Subtraction" (13), and "Multiplication \& Division of Radicals" (14) are moderately discussed. These students represent more than half of the twenty-one respondents of this study.

\section{Learning Experiences}

Thirteen (13) students agreed that the videos were able to capture and hold their attention, concise and have the ability to make them think while viewing the video. Fourteen (14) students agreed that the lesson is presented in a well-organized manner and that the language is clear and easy to understand. Twelve students (12) students agreed that the sound is clear and understandable, the visuals sharp and attractive. And it is worthy to note that out of twenty-one (21) students sixteen (16) agreed that the pacing of the video is comfortable. 


\section{Level of Effectiveness}

In Fractions, out of twenty-one (21) students, eight (8) perceived that the SSV is moderately effective (they learned enough), another eight (8) said it is quite effective (learned many things), four (4) perceived that it is slightly effective (learned a little), and only one (1) claimed that the SSV is very effective.

In Radicals, four (4) perceived that the SSV is slightly effective, eleven (11) said it is moderately effective, another set of four (4) students said it is quite effective, and two (2) claimed the SSV is very effective.

\section{Learning Outcomes}

In Fractions, twelve (12) out of twenty-one (21) students claimed that they learned enough from the video, five (5) said they learned a few things, three (3) said they learned much, and one (1) student learned a little.

In Radicals, eleven (11) students said they learned a few things, six (6) learned enough, three (3) learned much, and one (1) learned a little.

\section{Comments or Suggestions For Improvement of the Self-Study Video}

Analyzing the comments/suggestions given by the students for the improvement of the self-study video, it summarizes into two: 1) to include difficult examples and more exercises in the SSV, and 2) make SSV a little lively.

\section{CONCLUSIONS}

Based on the findings of the study, the researcher found it fitting to conclude the following:

1. That guided by an expert's theory in the teaching-learning process, a teacher could possibly create an innovative pedagogy in teaching a course. A teacher only needs to prepare way ahead in advance, planning is important.

2. For the academic achievement of the students in the traditional method, the maximum grade is 96, with minimum grade of 58. For the SSV, the maximum grade is 99 and the minimum is 56 . The median grade for both groups is equal at 75 . Looking into the mean grades, the traditional group performed a little bit higher at 77.33 than the SSV group of 77.05

3. The fitting of the SSV to the mathematics pedagogy does not affect students' academic achievement. The performance of the students in the traditional method is the same as the student that undergo learning through the use of self-study video. The finding also emphasized that pedagogy with technology is equally effective as the traditional method of teaching, thus, it may concluded that SSV may be used in place of the traditional method and still have the same result on the student's academic achievement.

\section{AUTHOR INFORMATION}

Dr. Leila R. Gano is a university professor from The University of the East, Manila under the Department of Mathematics and Statistics. She is a graduate of Doctor of Philosophy in Mathematics in 2004 and Doctor of Education in Management in 2010. She has written several researches on the use of technology in education and has it presented in international conferences. E-mail: leah_gano@yahoo.com 


\section{REFERENCES}

1. Diaz, D. P. \& Bontenbal, K. F. (2000). Pedagogy-Based Technology Training. In P. Hoffman, and D. Lemke (Eds.), Teaching and Learning in a Network World, (pp. 50-54). Amsterdam, Netherlands: IOS Press.

2. Kolb, Liz. Developing Everyday Technology Pedagogy In Preservice Teachers. University of Michigan, elikeren@umich.edu

3. Bal Krishnan Muniandy, Rossafri Mohammad2, Soon Fook Fong3.Synergizing pedagogy, learning theory and technology in instruction: How can it be done? Centre for Instructional Technology and Multimedia, University Sains Malaysia, Penang 11800, Malaysia

4. Basturk, Ramazan Ph.D. The Effectiveness of Computer-Assisted Instruction in Teaching Introductory Statistics. http://www.ifets.info/journals/8 2/16.pdf

5. Richardson, Kay and Rha Ilju, The Effect of Computer-Assisted Instruction on Mathematics Achievement of Fourth Graders. http://www.indiana.edu/ jopeng/Y603/rep2.html

6. Thomerson, J. D., Computer-assisted Instruction vs. Traditional instruction in an Advanced-level Computer Course. Valdosta State University, jthomers@ valdosta.edu

7. Bruner, Robert F., Repetition is the First Principle of All Learning (August 17, 2001). Available at SSRN: http://ssrn.com/abstract=224340

8. Teaching using digital video in secondary schools.

9. http://openlearn.open.ac.uk/mod/resource/view.php?id=211179

10. Gagne, Robert. Instructional Design Approach. http://www.gsu.edu/ mstswh/courses/it7000/papers/robert.htm

11. Kruse, Kevin. Gagne's Nine Events of Instruction. http://www.e-learningguru.com/articles/art3 3.htm

12. http://en.wikipedia.org/wiki/Pedagogy\#cite note-0

13. http://www.psychologicalscience.org/teaching/tips/tips 0703.cfm

14. http://www.bio-medicine.org/medicine-news/Interactive-Video--Better-Teaching-Aid-For-Toddlers-10325$\underline{1 /}$ 


\section{NOTES}

